\title{
LA ESTAFA COMO DELITO ECONÓMICO
}

[Fraud as a Commercial Crime]

\author{
Laura Mayer Lux* \\ Pontificia Universidad Católica de Valparaíso, Chile \\ InÊs Fernandes Godinho** \\ Universidade Lusófona do Porto, Portugal
}

\begin{abstract}
Resumen
El objetivo del trabajo es definir en qué supuestos y con qué alcance puede afirmarse que la estafa es un delito económico. Para ello se analizará la distinción entre bienes jurídicos individuales y colectivos, así como el objeto jurídico específicamente tutelado en los delitos económicos. Posteriormente se someterá a prueba la tesis, según la cual la estafa forma parte de la criminalidad económica,
\end{abstract}

\begin{abstract}
This work is aimed at determining on what assumptions and to what extent it can be asserted that fraud is a commercial crime. To do this, the distinction between individual and collective legal assets, as well as the legal subject matter specifically protected in commercial crimes will be analyzed. Then, although this is the crime against property per excellence, the thesis supporting that fraud is part of the
\end{abstract}

RECIBIDO el 23 de septiembre y ACEPTADo el 13 de diciembre de 2013

* Doctora en Derecho por la Rheinische Friedrich-Wilhelms-Universität Bonn; licenciada en Ciencias Jurídicas por la Pontificia Universidad Católica de Valparaíso. Profesora de Derecho penal en Pontificia Universidad Católica de Valparaíso. Correo electrónico: laura.mayer@ucv.cl

** Doctora y Magíster en Derecho por la Universidad de Coimbra; licenciada en Ciencias Jurídicas por la Universidad de Lisboa. Profesora de Derecho civil y de Derecho penal en la Universidad Lusófona de Porto. Correo electrónico: ines.godinho@ulp.pt. Este trabajo ha sido redactado en el marco del proyecto Fondecyt No 11121373: "La delimitación del tipo penal de estafa en el ordenamiento jurídico chileno”, dirigido por la profesora Laura Mayer Lux en la Pontificia Universidad Católica de Valparaíso. 
no obstante tratarse de un delito patrimonial por antonomasia. Para tal efecto se efectuará un análisis criminológico, de la interpretación doctrinal de ciertos casos de estafa, así como normativo-teleológico de la estafa en tanto delito económico. Finalmente, se indicarán las consecuencias que, en su caso, pueden derivarse de que la estafa sea un delito económico, sobre la base de las normas penales chilenas que regulan dicho tipo penal.

\section{Palabras Clave}

Bien jurídico individual - Bien jurídico colectivo - Fraudes colectivos - Delito patrimonial - Orden público económico. commercial crimes, will be tested. To do this, a crime analysis of the doctrinal interpretation of some fraud cases will be conducted, as well as a regulatory-teleological interpretation of fraud as a commercial crime. Finally, the consequences that, in this case, can be the result of the fact that fraud is a commercial crime based on the Chilean criminal norms that regulate such definition as crime, will be pointed out.

\section{KeYwords}

Personal legal asset - Collective legal asset - Collective Frauds - Crime against property - Economic public order.

\section{INTRODUCCIÓN}

Una revisión de diversas obras relativas al tipo penal estafa permite constatar que de acuerdo con una abrumadora mayoría, la estafa es considerada, ante todo, como un delito contra el patrimonio ${ }^{1}$. En estricto rigor, la estafa es una figura que lesiona intereses patrimoniales, pues de lo que se trata es de afectar el activo -y no el pasivo- del patrimonio de otra persona ${ }^{2}$. Como sea, algunos autores sostienen incluso que la estafa es el más relevante de los delitos contra intereses patrimoniales ${ }^{3}$, el delito patrimonial por antonomasia ${ }^{4}$, cuestión que permite afirmar que, junto con el hurto, la estafa es

${ }^{1}$ Véanse: Merkel, Adolf, Die Lehre vom strafbaren Betruge, en El Mismo, Kriminalistische Abhandlungen (reimpresión de la edición de Leipzig de 1867, Glashütten im Taunus, Detlev Auverman, 1971), II, pp. 56 ss.; FANELli, Andrea, La truffa (2a edición, Milano, Giuffrè, 2009), p. 58; Fernandes Godinho, Inês - Mayer Lux, Laura, A burla como crime contra o património: superação de uma tautologia, en Revista Portuguesa de Ciência Criminal, 2 (2011), pp. 237 ss.; Jiménez de AsúA, Luis, Crónica del crimen ( $7^{\text {a }}$ edición, Buenos Aires, LexisNexis, 2005), p. 322.

${ }^{2}$ Véase Rivacoba, Manuel de, El delito de contrato simulado (Santiago, ConoSur, 1992), pp. 17 ss.

${ }^{3}$ Cfr. Rengier, Rudolf, Strafrecht Besonderer Teil, I: Vermögensdelikte (13 edición, München, Beck, 2011), $\$ 13$, número marginal 1.

${ }^{4}$ Véase: Gaede, Karsten, $\delta 5$ 263-266b, en Leipold, Klaus - Tsambikakis, Michael - Zöller, Mark A. (editores), Anwaltkommentar StGB (Bonn, Deutscher Anwaltverlag, 2011), número marginal 1. 
uno de los pilares sobre los que se cimentan los delitos contra intereses de índole patrimonial.

Esa misma revisión de obras dedicadas al delito de estafa permite advertir, que para un importante sector de la doctrina la estafa constituye, bajo determinados supuestos, además de una figura contra intereses patrimoniales, un delito económico 5 , pasando con ello a ampliar el listado de tipos penales que integran la denominada criminalidad económica ${ }^{6}$. A ello se agrega que no pocas obras relativas al derecho penal económico, incluyen un estudio más o menos pormenorizado de la estafa común ${ }^{7}$, separado de aquel que se realiza respecto de figuras especiales de estafa, cuya vinculación con la criminalidad económica resulta más evidente. Tal es el caso, por ejemplo, de las estafas especiales consagradas en el Derecho penal alemán en materia de inversiones de capital ( $\$ 264$ a del Código Penal alemán) y de crédito $(\$ 265 \mathrm{~b}$ del mismo Código). Al estado de cosas descrito subyace la idea, destacada en la doctrina penal española, "de que las barreras diferenciadoras entre delitos patrimoniales y económicos no siempre son nítidas"

Ante un planteamiento como el aludido corresponde, en primer lugar, someter a prueba su corrección, esto es, establecer si acaso la estafa es, en determinados supuestos, un delito económico. Ello implica concebirla como un delito contra intereses individuales que, en ciertos casos, también afecta un bien jurídico colectivo o supraindividual. De constatarse la efectividad de latesis referida restará por determinar qué consecuencias pueden seguirse de la misma, de acuerdo con las normas penales chilenas que rigen dicho tipo delictivo.

${ }^{5}$ Para ello, véase el punto IV.

${ }^{6}$ De hecho, la criminalidad económica integra un universo variado: la criminalidad en la empresa, la criminalidad de la empresa e incluso la empresa ilícita. Cfr. Foffani, Luigi, Criminalidad organizada y criminalidad económica, en Revista Penal, 7 (Universidad de Huelva, 2001), p. 57.

${ }^{7}$ Véanse, a vía ejemplar: Fernández Albor, Agustín, Estudios sobre criminalidad económica (Barcelona, Bosch, 1978), pp. 46 ss.; Janssen, Gerhard, 5. Teil: Allgemeine Vermögensdelikte im Wirtschaftsstrafrecht, 1. Kapitel: Betrug, en AснеNBACH, Hans RANSIEK, Andreas (Editores), Handbuch Wirtschaftsstrafrecht (3a edición, München, C. F. Müller, 2012), números marginales 1 ss.; TöвBEns, Hans, Wirtschaftsstrafrecht (München, Vahlen, 2006), pp. 69 ss.

${ }^{8}$ Rubio Lara, Pedro Ángel, Parte especial de Derecho penal económico español (una aproximación al estado de la cuestión en la doctrina y jurisprudencia españolas) (Madrid, Dykinson, 2006), p. 14. 


\section{BIENES JURÍDICOS INDIVIDUALES Y BIENES JURÍDICOS COLECTIVOS: DEFINICIÓN, PARTICULARIDADES Y (LEGITIMIDAD DE SU) TUTELA PENAL}

Dentro de los intereses de relevancia penal y cuya (grave) afectación acarrea una sanción punitiva, es posible distinguir entre bienes jurídicos individuales y bienes jurídicos colectivos. Tradicionalmente se ha sostenido que los bienes jurídicos individuales son de titularidad ${ }^{9} \mathrm{o}$, en sentido análogo, sirven ${ }^{10}$ a una persona determinada o a un grupo de personas determinadas o determinables. En cambio, los bienes jurídicos colectivos, que también suelen denominarse supraindividuales ${ }^{11}$, son de titularidad o sirven a la "generalidad" 12 de las personas que integran el cuerpo social. Desde el punto de vista de su afectación, mientras que los delitos contra bienes jurídicos individuales inciden en personas concretas, los delitos contra bienes jurídicos colectivos "trasciende[n] la esfera de lo meramente individual"13, proyectando sus efectos negativos respecto de personas indeterminadas ${ }^{14}$.

El bien jurídico colectivo, a diferencia del individual, se caracteriza por permitir un goce general, no siendo exclusivo ni excluyente de persona alguna ${ }^{15}$. Esa posibilidad de disfrute "impersonal" 16 provoca que los individuos a quienes sirve el bien jurídico supraindividual tengan un legítimo interés en que éste se conserve como tal ${ }^{17}$. No se trata de que a cada individuo le corres-

${ }^{9}$ Véase: Birnbaum, Johann Michael Franz, Sobre la necesidad de una lesión de derechos para el concepto de delito (traducción de José Luis Guzmán Dalbora, Montevideo - Buenos Aires, B de F, 2010), p. 58.

${ }^{10}$ Cfr. Hefendehl, Roland, Kollektive Rechtsgüter im Strafrecht (Köln, Carl Heymanns Verlag, 2002), p. 19.

${ }^{11}$ Para una distinción entre los conceptos de interés colectivo, interés supraindividual, interés difuso, entre otros, véase: Aguirrezabal Grünstein, Maite, Algunas precisiones en torno a los intereses supraindividuales (colectivos y difusos), en Revista Chilena de Derecho, 33 (2006) 1, pp. 78 ss., con referencias ulteriores.

${ }^{12}$ KINDHÄUSER, Urs, Gefährdung als Straftat (Frankfurt am Main, Vittorio Klostermann, 1989), p. 144.

${ }^{13}$ Aguirrezabal Grünstein, Algunas precisiones, cit. (n. 11), p. 74.

${ }^{14}$ Así, la primera acepción de la voz "cualquiera" contenida en el Diccionario de la Real Academia Española. [disponible en http://rae.es/drae, fecha de consulta: 16 de septiembre de 2013].

${ }^{15}$ Véase Hefendehl, Kollektive Rechtsgüter im Strafrecht, cit. (n. 10), p. 111.

${ }^{16}$ En ese orden de ideas AguirreZabal GrünsteIn, Algunas precisiones, cit. (n. 11), p. 74 .

${ }^{17}$ Así Figueiredo Dias, Jorge de, Direito penal. Parte geral (2a edición, Coimbra, Coimbra Editora, 2007), p. 150; y Faria Costa, José de, Noçôes fundamentais de Direito penal (3a edición, Coimbra, Coimbra Editora, 2012), p. 269. 
ponda una porción del bien colectivo ${ }^{18}$, respecto de la cual pueda comportarse como si de un bien individual se tratara: el bien jurídico supraindividual no puede ser distribuido entre (algunos de) los sujetos que integran el cuerpo social, ya que este existe, íntegramente, para el uso pacífico y goce de todos ${ }^{19}$.

Sabido es que el Derecho penal se ha dedicado, en forma principal, a consagrar y castigar conductas (típicas, antijurídicas y culpables) que lesionan o ponen en peligro (concreto) bienes jurídicos individuales. El catálogo de intereses que subyace al Derecho penal nuclear se encuentra integrado por la vida, la salud, la libertad, la propiedad y el honor, esto es, por intereses que sirven en primer término a personas o a agrupaciones de personas determinadas o determinables.

Junto con los bienes jurídicos individuales han coexistido intereses supraindividuales de largo reconocimiento, v.gr. la fe pública y la recta administración de justicia, a través de figuras como la falsedad documental o la prevaricación judicial, respectivamente. A ellos se agregan diversos bienes jurídicos colectivos de reconocimiento penal más reciente, por ejemplo, intereses planteados y consagrados a nivel positivo a partir de los avances de la tecnología, v.gr. el ambiente o entorno y la identidad genética ${ }^{20}$; o bien, intereses reformulado ${ }^{21}$ a partir del fenómeno de la globalización ${ }^{22}$, v.gr. la

${ }^{18}$ Véase: Greco, Luís, Gibt es Kriterien zur Postulierung eines kollektiven Rechtsguts? en Heinrich, Manfred - Jäger, Christian - Achenbach, Hans - Amelung, Knut - Bottke, Wilfried - Haffke, Bernhard - Schünemann, Bernd - Wolter, Jürgen (editores), Strafrecht als Scientia Universalis, Festschrift für Claus Roxin zum 80. Geburtstag am 15. Mai 2011 (Berlin, De Gruyter, 2011), I, p. 203.

${ }^{19}$ Véase HefendeHL, Kollektive Rechtsgüter im Strafrecht, cit. (n. 10), p. 112.

${ }^{20}$ Sobre ello véase, por ejemplo: SuÁrEz GonzÁlez, Carlos, La función del Derecho penal y sus consecuencias para el genoma humano, en ZÚÑIGA RODRÍGUEZ, Laura - Méndez Rodríguez, Cristina - Diego Díaz-Santos, María Rosario (coordinadoras), Derecho penal, sociedad y nuevas tecnologías (Madrid, Colex, 2001), p. 153.

${ }^{21}$ Reformulados, pues la soberanía estatal impide plantear, por ejemplo, que la función pública sea el bien jurídico protegido por los actos de corrupción internacional, a diferencia de lo que acontece con la corrupción interna, en que tal dificultad no se produce.

${ }^{22}$ Para una aproximación relativa al vínculo entre la globalización y el ámbito económico, véase: ADAM, Christopher, Internationalization and Integration of Financial and Capital Markets, en Levy-Livermore, Amnon (editor), Handbookonthe Globalization of the World Economy (Cheltenham, Edward Elgar, 1998), pp. 557 s.; específicamente para dicho fenómeno en materia de Derecho penal económico: FARIA Costa, José de, O fenómeno da globalização e o Direito penal económico, en Almeida Costa, Mário Júlio - Ehrhardt Soares, Rogério - Castanheira Neves, António - Lopes Porto, Manuel Carlos - Faria Costa, José de (coordinadores), Estudos em Homenagem ao Prof. Doutor Rogério Soares (Coimbra, Coimbra Editora, 2001), p. 531. 
libre competencia y el orden económico internacional tratándose del llamado "soborno trasnacional"23.

Más allá del juicio que pueda efectuarse respecto de la tutela penal que hoy reciben los bienes jurídicos individuales y los intereses colectivos, no puede afirmarse en términos categóricos que para el legislador penal chileno los primeros tengan mayor relevancia que los segundos. Dejando fuera el caso del honor como interés individual, cuya afectación resulta secundaria atendida su baja penalidad -más por razones constitucionales que políticocriminales-, el protagonismo que han adquirido en el último tiempo bienes jurídicos individuales como la indemnidad sexual y la propiedad, se ha visto opacado por otros de índole supraindividual. Así acontece con el drástico régimen contenido en la Ley No $^{\circ} 20.000$ sobre tráfico ilícito de estupefacientes, en cuya base se encontraría un interés colectivo o supraindividual, a saber, la salud pública ${ }^{24}$.

Mientras que la relevancia penal de los bienes jurídicos individuales, en general, no suscita mayores discusiones a nivel doctrinal ${ }^{25}$, el carácter vaporoso y poco concreto de los intereses colectivos, así como su desvinculación de personas determinadas, provoca grandes dificultades a la hora de constituirlos en objetos jurídicos de figuras delictivas. Es, precisamente, esta falta de especificación de los sujetos afectados lo que lleva a algunos a aludir a intereses colectivos o "difusos" ${ }^{26}$. Pese a lo extendido del término, dicha denominación resulta equívoca, pues puede llevar a pensar que lo difuso es el contenido y no el titular del bien supraindividual. En realidad, la legitimidad de la tutela punitiva de un interés colectivo pasa, no sólo por (re)formularlo de acuerdo con los tiempos que corren, sino que, principalmente, por precisar

${ }^{23}$ Benavides Schiller, Andrés, Acerca de la corrupción pública y privada en España a la luz de los delitos contra la Administración Pública (Título XIX del Libro II CP Español), en Cuadernos de Politica Criminal, 108 (diciembre de 2012) 3, pp. 121 ss.

${ }^{24}$ Véase: Politoff, Sergio - Matus, Jean Pierre - Ramírez, María Cecilia, Lecciones de Derecho penal chileno. Parte especial (2 a edición, Santiago, Editorial Jurídica de Chile, 2005), pp. 573 ss.

${ }^{25}$ Siendo el honor el interés que, en general, provoca mayores dificultades, tanto por su constante colisión con ciertos derechos constitucionales, v.gr. la libertad de expresión e información, como por su compleja delimitación conceptual. Sobre ello: ScHOPenhauer, Arthur, Die Kunstsich Respektzuverschaffen (München, Beck, 2011), pp. 28 ss., así como Labatut Glena, Gustavo, Derecho penal (7a edición actualizada por el profesor Julio Zenteno Vargas, Santiago, Editorial Jurídica de Chile, 2012), II, p. 181.

${ }^{26}$ Aguirrezabal Grünstein, Algunas precisiones, cit. (n. 11), pp. 69 ss. Véase también BARATta, Alessandro, Funciones instrumentales y simbólicas del derecho penal: una discusión en la perspectiva de la criminología critica (1991), ahora, en EL Mismo, Criminología y Sistema Penal (Montevideo - Buenos Aires, B de f, 2004), p. 67. 
claramente su contenido, descartando definiciones vagas y abstractas ${ }^{27}$, que sólo favorecen una aplicación caprichosa de la norma penal.

La protección de los bienes jurídicos supraindividuales debe ser limitada, en el sentido de que éstos sólo deben ser tutelados penalmente en caso que puedan ser inferidos "a partir de intereses individuales" ${ }^{28}$. No debe perderse de vista que los bienes jurídicos se identifican con aquellas condiciones materiales e inmateriales ${ }^{29}$ de las personas, cosas o instituciones, que sirven al libre desarrollo del individuo en un Estado democrático de Derecho ${ }^{30}$. Desde un punto de vista constitucional, el Estado está al servicio de la persona -y no la persona al servicio del Estado- y su finalidad es promover el bien común, para lo cual, debe tener en cuenta la creación y preservación de todas aquellas condiciones que posibiliten la au torrealización del individuo (artículo 1, inciso $4^{\circ} \mathrm{CPol}$.).

Si algún sentido tiene sostener que el Derecho penal "tutela" objetos jurídicos, tratándose de bienes colectivos, esa protección no se efectúa "en interés exclusivo del Estado y de su poder de control"31. Los bienes jurídicos supraindividuales no son tutelados en cuanto tales, sino sólo en la medida en que implican una afectación de intereses concretos que sirven al individuo. Desde este punto de vista tienen razón quienes plantean que la distinción entre bienes jurídicos individuales y colectivos, según si su titular sea el individuo o la comunidad, es equívoca: "la determinación de los bienes jurídicos se habrá de hacer considerando los individuos y sus necesidades antes que la conservación y funcionamiento del sistema social" ${ }^{\prime 2}$.

${ }^{27}$ En el mismo orden de ideas Bustos Ramírez, Juan, Obras Completas. Derecho penal. Parte general (2a edición, Santiago, Ediciones Jurídicas de Santiago, 2007), I, p. 68.

${ }^{28}$ Sternberg-Lieben, Detlev, Bien jurídico, proporcionalidad y libertad del legislador penal, en HEFENDEHL, Roland (editor), La teoría del bien jurídico ¿Fundamento de legitimación del Derecho penal o juego de abalorios dogmático?(Madrid, Marcial Pons, 2007), p. 109.

${ }^{29}$ Guzmán Dalbora, José Luis, “Estudio Preliminar” a Birnbaum, Johann Michael Franz, Sobre la necesidad de una lesión de derechos para el concepto de delito (Montevideo - Buenos Aires, B de F, 2010), p. 30.

${ }^{30} \mathrm{Cfr}$. Kindhäuser, Urs, Strafrecht Allgemeiner Teil ( $5^{\text {a }}$ edición, Baden-Baden, Nomos, 2011), $\$ 2$, número marginal 6. También Sternberg-Lieben, Bien jurídico, cit. (n. 28), p. 110.

${ }^{31}$ TAVAREs, Juárez, Bien jurídico y función en Derecho penal (traducción de Mónica Cuñarro, Buenos Aires, Hammurabi, 2004), p. 72.

${ }^{32}$ Hormazábal Malarée, Hernán, Bien jurídico y estado social y democrático de derecho ( $2^{a}$ edición, Santiago, LexisNexis, 2006), p. 135. De ahí que dicho autor distinga entre bienes jurídicos de carácter microsocial y bienes jurídicos de carácter macrosocial (cfr. obra y página citadas). 


\section{EL BIEN JURÍDICO SUBYACENTE A LOS DELITOS ECONÓMICOS: DEFINICIÓN, SISTEMATIZACIÓN Y LÍMITES}

En el intento por delimitar la categoría de "delito económico" sobre la base de un bien jurídico común, es posible advertir planteamientos restrictivos, intermedios y amplios de la idea de criminalidad económica. En efecto, algunos autores utilizan un concepto estricto de delito económico ${ }^{33}$, en el que ubican fundamentalmente los atentados a la libre competencia ${ }^{34}$, pero también otros, v.gr. las conductas contrarias al comercio exterior ${ }^{35}$. Otros extienden dicha noción a delitos que pueden integrar la criminalidad nuclear o la propiamente económica, como ocurre con ciertos fraudes cometidos en los ámbitos bursátil o crediticio ${ }^{36}$, así como con la usura ${ }^{37-38}$. También es

${ }^{33}$ Linares Estrella, Ángel, Un problema de la parte general del Derecho penal económico (Granada, Comares, 2002), p. 41.

${ }^{34}$ Véase: Righi, Esteban, Los delitos económicos (Buenos Aires, Ad Hoc, 2000), pp. 194 ss., 205 ss. Sobre el problema -vinculado con el delito de estafa- de la consagración de los acuerdos de precios como atentados contra la libre competencia en el Código Penal chileno, véanse: Hernández Basualto, Héctor, La punibilidad de la colusión (secreta) de precios en el derecho chileno, en Política Criminal, 7 (2012) 13, pp. 147 ss. Disponible en http://www.politicacriminal.cl/Vol_07/n_13/Vol7N13A4.pdf [fecha de consulta: 16 de septiembre de 2013]; y Matus, Jean Pierre, Acerca de la actual falta de punibilidad en Chile de los acuerdos de precios, en Politica Criminal, 7 (2012) 14, pp. 318 ss., disponible en http://www.politicacriminal.cl/Vol_07/n_14/Vol7N14A3. pdf [fecha de consulta: 16 de septiembre de 2013].

${ }^{35}$ Así Achenbach, Hans, Wirtschaftskriminalität und Wirtschaftsstrafrecht. Gedanken zu einer terminologischen Bereinigung, en Feltes, Thomas - Pfeiffer, Christian - Steinhilper, Gernot (editores), Kriminalpolitik und ibre wissenschaftiche Grundlagen, Festschrift für Professor Dr. Hans-Dieter Schwind zum 70. Geburtstag (Heidelberg, C. F. Müller, 2006), p. 186.

${ }^{36}$ Cfr. Oтто, Harro, Grundkurs Strafrecht, Die einzelnen Delikte (7a edición, Berlin, De Gruyter, 2005), p. 319, número marginal 28 y pp. 320 s., números marginales $38 \mathrm{~s}$.

${ }^{37}$ Fundamental es: Отто, Grundkurs Strafrecht, cit. (n. 36), p. 335, número marginal 124. Destaca el carácter económico de la usura, además del estrictamente patrimonial: Tiedemann, Klaus, WirtschaftsstrafrechtBesondererTeil ( $3^{a}$ edición, München, Vahlen, 2011), número marginal 258.

${ }^{38}$ Casos más dudosos de "delitos económicos", son determinados ilícitos penales que lesionan el patrimonio del Estado, como ciertos delitos tributarios y aduaneros. Sobre el bien jurídico protegido por los delitos tributarios véase: VAN WeEzel, Alex, Delitos tributarios (Santiago, Editorial Jurídica de Chile, 2007), pp. 14 ss., quien distingue entre el modelo "patrimonialista" y el "institucionalista". Para el interés tutelado en los delitos aduaneros véase: Rodríguez Collao, Luis - Ossandón Widow, María Magdalena, Delitos aduaneros (Santiago, Editorial Jurídica de Chile, 2010), pp. 64 ss.; Guzmán Dalbora, José Luis, Contrabando y fraude aduanero (Valparaíso, Edeval, 1998), pp. 26 ss., quien defiende la afectación de intereses patrimoniales estatales. A 
posible, en fin, recurrir a un concepto omnicomprensivo de criminalidad económica ${ }^{39}$, en el que prácticamente sólo quedan fuera los delitos contra la libertad y el honor, pues incluso la salud y hasta la vida pueden resultar afectadas con la comisión de ciertos delitos supuestamente económicos, v.gr. los que atentan contra la salud pública por la comercialización de productos defectuosos ${ }^{40}$.

Las teorías restrictivas del concepto de criminalidad económica tienen la virtud de aglutinar, en torno a un interés más o menos preciso y distinguible de otros, una serie de delitos que, sin hacer referencia al mismo no podrían ser explicados satisfactoriamente. En ese orden de ideas, para determinar la relevancia del concepto de criminalidad económica respecto de los atentados a la libre competencia, la usura, los fraudes, los delitos contra el ambiente o el entorno, los delitos informáticos o aun los tipos penales vinculados con la corrupción, entre otros, debe responderse la siguiente interrogante: jes posible explicar cabalmente el injusto de tales comportamientos sin recurrir a la noción de criminalidad económica? Sólo si la respuesta es negativa, quedará demostrado que el recurso a dicho concepto es relevante o incluso determinante para la comprensión de la conducta típica. Por el contrario, si puede prescindirse de la referencia a la criminalidad económica para explicar el injusto de un específico delito, se habrá constatado que el recurso a aquél concepto es lisa y llanamente superfluo.

La mayoría de las aproximaciones doctrinales (más o menos) restrictivas del interés penalmente protegido en los delitos económicos, se distinguen fundamentalmente en la terminología y en la clasificación conceptual que proponen, y no en cuestiones sustantivas. Así, se alude de forma equivalente a la economía o al orden (público) económico como objeto de tutela penal, indicando, para efectos de sistematización y con más o menos matices, qué aspectos concretos de la economía o del orden (público) económico resultan afectados con un determinado comportamiento. Desde un punto de vista más laxo, en cambio, se considera la idea de economía como un valor amplio, que se encuentra fragmentado en bienes jurídicos más concretos, muchos

favor de que los delitos aduaneros sean entendidos como delitos económicos "en sentido estricto" véase: Vidal Albarracín, Héctor Guillermo, Delitos aduaneros (2a edición, Corrientes, Mave, 2006), p. 33; a favor del carácter económico y no puramente patrimonial de los delitos tributarios, por su parte: Alvarado Urízar, Agustina, Delitos de emprendimiento en el Código Tributario (Santiago, Librotecnia, 2011), p. 184.

${ }^{39}$ Véase: Martínez-Buján Pérez, Carlos, Derecho penal económico y de la empresa. Parte especial (4a edición, Valencia, Tirant lo Blanch, 2013), pp. 44 ss.; TöвBEns, Wirtschaftsstrafrecht, cit. (n. 7), pp. 67 ss.; WITTIG, Petra, Wirtschaftsstrafrecht (2 $2^{\text {a }}$ edición, München, Beck, 2011), \$\$14 ss.

${ }^{40}$ García Cavero, Percy, Derecho penal económico. Parte general (2a edición, Lima, Grijley, 2007), I, pp. 54 s. 
de los cuales forman parte de la criminalidad tradicional, como ocurre con los intereses de índole patrimonial.

Según un primer planteamiento doctrinal, los delitos económicos tienen como objeto de protección penal a la economía, pero no como un hecho, o como un fenómeno complejo de carácter cultural o social ${ }^{41}$, sino que entendida como norma, como regulación jurídica de la riqueza ${ }^{42}$. Podrá advertirse que definir la economía como "regulación" no se diferencia de emplear dicho concepto en el sentido de "orden" económico. Como sea, proteger la economía implica, entre otros aspectos, el establecimiento de reglas para la producción y la adquisición de bienes y servicios existentes en un momento y lugar determinados ${ }^{43}$. Dicha labor puede realizarse a través de diversos instrumentos jurídicos, surgiendo la duda de si la tutela propiamente penal de la economía puede lograrse recurriendo a los delitos que tradicionalmente han protegido los intereses patrimoniales o si, en cambio, se requiere una tipificación particular, que incorpore factores que excedan bienes jurídicos de carácter individual.

Según la doctrina mayoritaria, los delitos económicos tienden a la protección del "orden económico", noción que, más allá de la idea de regulación que le es propia, no tiene un sentido unívoco. Para una primera variante de dicha concepción, el orden económico es la "regulación jurídica de la producción, [la] distribución y [el] consumo de bienes y servicios" ${ }^{\text {"44. Otros }}$ autores acotan la idea de orden económico al añadirle un carácter público, definiéndolo como la "regulación jurídica de la participación estatal en la economía” ${ }^{3}$. Dicha participación estatal no se vincula únicamente con la

${ }^{41}$ Miranda, Rafael, Delitos contra el orden económico (Buenos Aires, Ediciones Pannedille, 1970), p. 26.

${ }^{42}$ Véase Faria Costa, José de, Direito penal económico (Coimbra, Editorial Quarteto, 2004), p. 41.

${ }^{43}$ En ese orden de ideas, véanse: BoRINSKY, Mariano, Enfoque criminal y económico a propósito de prácticas anticompetitivas y vulneración de precios máximos, en RUBINsKA, Ramiro M. - Schurjin Almenar, Daniel (coordinadores), Derecho penal económico (Buenos Aires, Marcial Pons, 2010), I, p. 847; y Oтто, Grundkurs Strafrecht, cit. (n. 36), p. 313, número marginal 4.

${ }^{44}$ Cervini, Raúl, Aproximación conceptual integrada al Derecho penal económico, en Rubinska, Ramiro M. - Schurjin Almenar, Daniel (coordinadores), Derecho penal económico (Buenos Aires, Marcial Pons, 2010), I, p. 35; Rubio Lara, Parte especial de Derecho penal económico Español, cit. (n. 8), p. 19.

${ }^{45}$ Martínez-Buján Pérez, Carlos, Derecho penal económico y de la empresa. Parte general ( $2^{a}$ edición, Valencia, Tirant lo Blanch, 2007), p. 169. Véase también BAJO, Miguel - Bacigalupo, Silvina, Derecho penal económico (Madrid, Centro de Estudios Ramón Areces, 2001), p. 14, para quienes el delito económico es "la infracción jurídico-penal que lesiona o pone en peligro el orden económico entendido como regulación jurídica del intervencionismo estatal en la Economía de un país"; SCHMIDT, Eberhard, 
actividad empresarial, sino que se extiende a muchos otros ámbitos, dentro de los que destacan las actuaciones públicas de control, por ejemplo, a través del Banco Central o de las diversas Superintendencias. En fin, hay quienes relacionan el concepto de orden económico con el "interés económico sectorial de un grupo interviniente en el mercado" 46 , ámbito en el que interactúan tanto "oferentes" como "consumidores" ${ }^{47}$ de bienes y servicios.

Como sea, independiente del concepto de orden (público) económico que se sostenga, quienes intervienen en el mercado presuponen el respeto de ciertas reglas mínimas, las cuales permiten desarrollar una confianza recíproca ${ }^{48}$, que incide en las decisiones económicas de los sujetos. Desde un punto de vista jurídico penal, dicha confianza es una "confianza con contenido económico", que puede manifestarse en la creencia de que, por ejemplo, no se cobrarán más intereses de los que legalmente son permitidos; que no se adquirirán acciones utilizando información privilegiada; que no se manipulará el mercado mediante colusiones (secretas) de precios; entre otros.

Faria Costa ${ }^{49}$ postula una sistematización de la criminalidad económica, dividiéndola en cuatro grandes grupos y cubriendo, con ello, la macroeconomía, la microeconomía, el patrimonio del Estado y los intereses de la colectividad o del consumidor. De acuerdo con él, es posible distinguir: i) normas penales para la protección de la economía financiera estatal; ii) normas penales para la protección de la economía nacional; $i i i)$ normas penales para la protección de la economía de la empresa; y $i v$ ) normas penales para la protección de la colectividad y el consumidor. Todas estas normas tendrían en común la imposición de una pena frente a la realización de un comportamiento que afecte gravemente a la economía o al orden (público) económico.

Sea que se postule que el bien jurídico de los delitos económicos es la economía en sí misma o el orden (público) económico, estamos ante un interés supraindividual o colectivo. Consiguientemente, una tipificación

Das neuewestdeutsche Wirtschaftsstrafrecht (Tübingen, Mohr, 1950), pp. 50 s., quien concibe los delitos económicos como aquellas infracciones que lesionan los intereses públicos en la existencia y mantención del orden económico establecido por el Estado y necesario para que éste pueda llevar a cabo sus tareas económicas superiores.

${ }^{46}$ Martínez-Buján, Derecho penal económico y de la empresa. Parte general, cit. (n. 45), p. 169 quien, con ello, plantea otra faceta del concepto que desarrolla.

${ }^{47}$ De acuerdo con el artículo 1 de la Ley $\mathrm{N}^{\circ} 19.496$, que establece normas sobre protección de los derechos de los consumidores, "consumidores" o "usuarios" son "las personas naturales o jurídicas que, en virtud de cualquier acto jurídico oneroso, adquieren, utilizan, o disfrutan, como destinatarios finales, bienes o servicios [...]".

${ }^{48}$ Véase Navarro Cardoso, Fernando, Algunas consideraciones sobre las estafas colectivas a los consumidores, en Revista del Poder Judicial, 50 (1998), pp. $169 \mathrm{s.}$

${ }^{49}$ Cfr. Faria Costa, Direito penal económico, cit. (n. 42), pp. 27 s. 
legítima de los delitos económicos supone que la economía o el orden (público) económico no se tutelen en cuanto tales, sino sólo en la medida en que constituyan un "instrumento al servicio de los ciudadanos" ${ }^{\text {". El sentido que }}$ tiene el concepto de bien jurídico es, ante todo, la protección de la persona ${ }^{51}$, no pudiendo los intereses económicos de la sociedad constituir fines en sí mismos, sino que simples medios al servicio del individuo ${ }^{52}$.

De otro lado, siendo la economía o el orden (público) económico un interés colectivo subyacente a la criminalidad económica, su precisión conceptual y su real afectación constituyen presupuestos ineludibles de la consagración y aplicación legítimas de la norma penal. El Derecho penal económico es, en primer término, Derecho penal, de modo que ha de respetar todos aquellos principios que rigen tanto el Derecho penal material ${ }^{33}$ como el Derecho procesal penal, destacando los principios de taxatividad y ofensividad, así como el de presunción de inocencia ${ }^{54}$, respectivamente.

\section{LA ESTAFA COMO DELITO GENERALMENTE PATRIMONIAL Y EXCEPCIONALMENTE ECONÓMICO}

\section{La estafa como delito económico desde un punto de vista criminológico.}

Desde una perspectiva criminológica, los delitos económicos han estado fuertemente influidos por los planteamientos de Sutherland relativos a la "criminalidad de cuello blanco" ${ }^{\text {5 }}$. El criminal de cuello blanco es referido como el prototipo de "delincuente económico", noción no exenta de inconvenientes, pues sitúa en el centro del análisis al autor y no a su conducta ${ }^{56}$.

${ }^{50}$ Rodríguez Collao, Luis - Ossandón Widow, María Magdalena, Delitos contra la función pública (2a edición, Santiago, Editorial Jurídica de Chile, 2008), p. 102, a propósito de los delitos que son objeto de dicha obra.

${ }^{51}$ Cfr. Marx, Michael, Zur Definition des Begriffs "Rechtsgut" (Köln, Carl Heymanns Verlag, 1972), p. 81.

${ }^{52}$ De otra forma: Tiedemann, Klaus, Tatbestandsfunktionen im Nebenstrafrecht, Untersuchungen zu einem rechtsstaatlichen Tatbestandsbegriff, entwickelt am Problem des Wirtschaftsstrafrechts (Tübingen, Mohr, 1969), pp. 118 s.

${ }^{53}$ Véase: KINDHÄUSER, Urs, Zur Legitimität der abstrakten Gefährdungsdelikte im Wirtschaftsstrafrecht, en Schünemann, Bernd - SuÁrez González, Carlos (Editores), Bausteine des europäischen Wirtschaftsstrafrechts, Madrid-Symposium für Klaus Tiedemann (Köln, Carl Heymanns Verlag, 1995), p. 125; RigHI, Los delitos económicos, cit. (n. 34), pp. 53 ss.

${ }^{54}$ Cfr. Aller, Germán, Derecho penal económico y delitos del poder, en Anuario de Derecho Penal Económico y de la empresa, 2 (2012), p. 10.

${ }^{55}$ Véase: Sutherland, Edwin, White Collar Criminality, en American Sociological Review, 5 (1940), pp. 1 s.

${ }^{56}$ En ese sentido ACHENBACH, Wirtschaftskriminalität und Wirtschaftsstrafrecht, cit. (n. 35), p. 182; Ortiz Quiroga, Luis, Delincuencia económica, en AA.VV, Pro- 
Como sea, a partir de la tesis de Sutherland se difundió la idea de que el estudio de la criminalidad no podía concentrarse exclusivamente en individuos provenientes de las clases sociales más desposeídas, sino que también debía tener en cuenta la comisión de delitos por parte de sujetos que gozan de prestigio y posición social ${ }^{57}$.

Sostener que la estafa, desde un punto de vista criminológico, puede ser entendida como un delito económico, requiere efectuar algunas precisiones. Por de pronto, de seguirse el planteamiento de Sutherland, los supuestos de estafa que sean considerados dentro de la criminalidad económica no tienen que ser cometidos, necesariamente, por un hombre de negocios, que interactúa comunicativamente al interior de una empresa o desde su despa$\mathrm{cho}^{58}$. Decisivo en el perfil delictivo descrito por Sutherland es el concepto de respetabilidad social ${ }^{59}$, la cual, no parece un atributo que hoy por hoy se vincule de manera natural con el hombre de negocios. Por el contrario, la cada vez más difundida idea del ciudadano como consumidor y del hombre de negocios como sujeto asiduo a los abusos, más bien favorece la desconfianza y hasta la sospecha entre quienes intervienen en el tráfico jurídico.

El autor del delito de estafa, entendido como delito económico, puede asumir las más diversas caretas. Si de lo que se trata, siguiendo a Sutherland, es de que el sujeto activo tenga un cierto prestigio o posición social, dichas características pueden darse respecto de un hombre de negocios, o bien, de una señora de edad avanzada de quien jamás se sospecharía la comisión delictiva. Así aconteció hace algunos años en la tristemente célebre "estafa de los quesitos", que habría liderado la ciudadana francesa Gilberte van Erpe, conocida popularmente como "Madame Gil" ${ }^{60}$. Un caso como el aludido

blemas Actuales de Derecho Penal (Temuco, Universidad Católica de Temuco, 2003), p. 193.

${ }^{57}$ Cfr. Sutherland, Edwin - Cressey, Donald, Criminology ( 8 a edición, Philadelphia, J. B. Lippincott, 1970), pp. 75 s. Véase también: BoRINSKY, Enfoque criminal y económico, cit. (n. 43), p. 848. A juicio de Righi, Los delitos económicos, cit. (n. 34), pp. 76 s., ello habría acercado los conceptos de poder económico y poder político, "dando lugar a que en la teoría de la criminalidad de cuello blanco se incluyeran hipótesis de corrupción realizadas por altos funcionarios del sector público".

${ }^{58}$ Sobre la descripción de esta clase de supuestos, en oposición a la criminalidad callejera, véase: AlLER, Derecho penal económico y delitos del poder, cit. (n. 54), pp. 16 s.

${ }^{59}$ Véase: Sutherland, Edwin, White Collar Crime, The Uncut Version (New Haven, Yale University Press, 1983), p. 7.

${ }^{60} \mathrm{Si}$ bien la resolución definitiva de dicho caso aún se encuentra pendiente, van Erpe habría actuado en Chile a través de la empresa de lácteos Fermex S.A., creada hacia fines del año 2004 y utilizada para perjudicar patrimonialmente a unas 5.000 personas. Lo mismo habría acontecido en el Perú a través de la firma Labomax, país en el que se estima que las víctimas de la estafa de van Erpe ascienden a 25.000. En ambos países, los afectados por dicho fraude colectivo, llevado a cabo a través de un negocio "pirami- 
no debe extrañarnos, pues para cometer el delito de estafa resulta indispensable engañar a otro, persuadir al disponente, venciendo la mayor o menor desconfianza natural de quien es parte de una relación negocial concreta ${ }^{61}$. Y qué mejor manera de lograrlo que ejecutándolo una mujer de entrados años, que aparenta ser incapaz de cometer delito.

Interesante de la estafa por la que se acusa a "Madame Gil" es el fundamento de su consideración como delito económico. De seguirse el planteamiento de Sutherland, diríamos que la autora cumplió con el perfil del delincuente económico, pese a no vestir "cuello y corbata”. Y lo cumplía, pues se trataba de una mujer que gozaba de buen crédito o confianza social, características que empleó a su favor para timar a sus víctimas. Existe, sin embargo, otra forma de entender que un caso como el indicado sea un delito económico: atender, ya no a las características o a la forma de ser del hechor (perfil criminal), sino que a las particularidades y consecuencias de su hecho (fenómeno criminal).

Sobre la base de lo indicado puede afirmarse, que la "estafa de los quesitos" constituyó un delito económico, porque además de lesionar un bien jurídico individual, a saber, los intereses patrimoniales de los afectados, incidió en un interés de dimensiones supraindividuales, atendida la extensión del perjuicio provocado. ${ }^{62}$ Ello no se vincula exclusivamente con la cuantía del daño causado, pues éste, por sí solo, no altera la naturaleza del delito. Así, por ejemplo, no porque el monto de un supuesto de fraude al fisco sea sideral podrá aseverarse, por ese solo hecho, que dicho delito dejó de ser una figura contra la función pública y el patrimonio fiscal, para pasar a ser un tipo penal contra la economía o el orden (público) económico. Lo mismo puede decirse de un supuesto de estafa cometido en contra de una sola víctima y en que el monto de lo defraudado equivalga a varios millones de dólares, circunstancia que, por sí sola, no transforma a esa estafa en un delito económico. Por el contrario, para sostener que un caso de estafa forma parte de la criminalidad económica, es necesario que se afecten los intereses patrimoniales de un gran número de personas y, con ello, el orden (público) económico. ${ }^{63}$

dal", debían pagar cerca de 250.000.- pesos chilenos a cambio de unos "hongos" que, al fermentar y adquirir el aspecto de "quesos", serían adquiridos por Fermex o Labomax, respectivamente, por el doble de lo pagado por los afectados, para luego enviarlos a Francia, donde serían empleados en la industria de los cosméticos.

${ }^{61}$ Cfr. Choclán Montalvo, José Antonio, El delito de estafa (Barcelona, Bosch, 2000), p. 22.

${ }^{62}$ En ese sentido: ACHENBACH, Wirtschaftskriminalität und Wirtschaftsstrafrecht, cit. (n. 35), p. 187.

${ }^{63}$ Para ello, véase el punto IV, 3. 


\section{La distinción doctrinal entre la estafa común y ciertos casos de "estafas} especiales" que integrarían la criminalidad económica.

La estafa es, ante todo, un delito contra intereses patrimoniales ${ }^{64}$. Sin embargo, de acuerdo con un sector de la doctrina ${ }^{65}$, el delito de estafa puede implicar (secundariamente) un atentado contra intereses colectivos que exceden el patrimonio individual y que se identifican con la economía o el orden (público) económico. Según dicho planteamiento, cuando la estafa, además de lesionar el patrimonio, afecte la economía o el orden (público) económico, tendrá el carácter de delito patrimonial y económico. En ese orden de ideas, la estafa podría tener una naturaleza híbrida o dual, como delito patrimonial y económico, en todos aquellos supuestos en que intereses patrimoniales individuales y la economía o el orden (público) económico, en tanto interés supraindividual, resulten afectados con el comportamiento delictivo.

Fernández Albor, comentando la regulación española vigente con anterioridad al Código Penal de 1995, cuyo modelo casuístico fue prácticamente reproducido en el Código penal chileno, plantea que la finalidad político criminal de dicha tipificación de la estafa es la tutela del tráfico mercantil, no obstante se demande, para imponer la pena, que se afecte un derecho patrimonial individual ${ }^{66}$. En realidad, la descripción típica del Código Penal español y, con ella, la del Código chileno, abonaba esta teoría al contemplar, en su artículo 529, figuras de estafa en que se engañaba, por ejemplo, aparentando bienes, crédito, saldo en cuenta corriente, comisión, empresa o negociaciones imaginarias. Pues bien, fácil es vincular dichos supuestos de engaño con el que podría cometer quien pretende el otorgamiento de un crédito, que es, precisamente, uno de los casos de "estafa" ${ }^{67}$ que la doctrina alemana -no sin inconvenientes $^{68}$ - incluye dentro de la criminalidad económica ${ }^{69}$.

${ }^{64}$ Para ello, véase el punto I, introductorio del presente trabajo.

${ }^{65}$ Cfr. Choclán Montalvo, El delito de estafa, cit. (n. 61), pp. 16 ss.; Töвbens, Wirtschaftsstrafrecht, cit. (n. 7), pp. 69 ss.; WITTIG, Wirtschaftsstrafrecht, cit. (n. 39), $\$ \$ 14$ ss. Véase también TiEdEMANN, Wirtschaftsstrafrecht, cit. (n. 37), números marginales 145 ss., 330 ss., 351 ss.

${ }^{66}$ FERNÁNDEZ Albor, Estudios sobre criminalidad económica, cit. (n. 7), pp. $47 \mathrm{~s}$.

${ }^{67}$ Ya que la conducta se consuma con el solo engaño del sujeto activo, el delito contempla una forma de fraude -y no de estafa- en materia crediticia.

${ }^{68}$ En realidad, la consagración de dicha figura en el Derecho penal alemán ha servido ante todo para proteger, a través de un delito de peligro abstracto, intereses patrimoniales de la institución financiera que otorga el crédito de que se trate. En sentido análogo: Greco, Gibt es Kriterien zur Postulierung eines kollektiven Rechtsguts? cit. (n. 18), p. 201 en relación con p. 213. También crítico de dicha figura, por no suponer "el aseguramiento de las condiciones inmediatas del desarrollo de la persona" STERNBERG-Lieben, Bien jurídico, cit. (n. 28), p. 111.

${ }^{69}$ Básicamente, en la "estafa" de crédito del $\$ 265$ b del Código Penal alemán, el 
También se considera parte integrante de la delincuencia económica la "estafa en materia de inversiones de capital"70, que en el Derecho alemán supone realizar engaños activos u omisivos en prospectos de inversiones, fundamentalmente respecto del valor de una sociedad. ${ }^{71}$ Igualmente se menciona el fraude de seguros ${ }^{72}$, el cual es definido como una "modalidad de estafa cometida con el fin de obtener, mediante engaño, una prestación que el asegurador no está obligado a realizar"73. En fin, un sector de la doctrina sostiene que incluso el fraude o "estafa" de subvenciones forma parte de los delitos que afectan la economía o el orden (público) económico, ${ }^{74}$ idea que de ser efectiva podría extenderse a todas las figuras delictivas que afectan el patrimonio estatal, v.gr. ciertos delitos tributarios y aduaneros.

La ambivalencia que exhibiría el tipo penal de estafa también se presentaría en otros comportamientos delictivos. Así, por ejemplo, en la falsificación de instrumentos mercantiles sería posible advertir, en determinados supuestos, tanto un atentado contra la funcionalidad del documento, que debe darse en todo caso, como, de pasada, contra la economía o el orden (público) económico ${ }^{75}$. De esta manera, adquiriría el carácter de delito económico una figura que, al igual que la estafa, integra los tipos penales tradicionales ${ }^{76}$. Lo mismo acontecería con los delitos concursales que, según la doctrina mayoritaria, constituyen figuras de daño contra los intereses

agente debe llevar a cabo un engaño activo u omisivo sobre su capacidad de pago del crédito a contraer. Respecto de dicha figura véase WITTIG, Wirtschaftsstrafrecht, cit. (n. 39), $\$ 19$, número marginal 5.

${ }^{70}$ En rigor, puesto que la conducta del $\$ 264 a$ del Código Penal alemán se consuma con el solo engaño del sujeto activo, dicho delito consagra una forma de fraude $-y$ no de estafa- en materia de inversiones de capital.

${ }^{71}$ Para más detalles: Tiedemann, Wirtschaftsstrafrecht, cit. (n. 37), números marginales 345 ss. Crítico de la consagración de dicho delito, y con razón, KINDHÄUSER, Zur Legitimität der abstrakten Gefährdungsdelikteim Wirtschaftsstrafrecht, cit. (n. 53), p. 133.

${ }^{72}$ Cfr. Otтo, Grundkurs Strafrecht, cit. (n. 36), p. 314, número marginal 1.

${ }^{73}$ Piña Rochefort, Juan Ignacio, Fraude de seguros. Cuestiones penales de técnica legislativa (2a edición, Santiago, Editorial Jurídica de Chile, 2006), p. 24.

${ }^{74}$ Véase, por ejemplo: Choclán Montalvo, El delito de estafa, cit. (n. 61), p. 20; y Martínez-Buján Pérez, Derecho penal económico y de la empresa. Parte especial, cit. (n. 39), pp. 739 ss.

${ }^{75}$ Para la falsificación de títulos valores como conducta que afecta la función de los medios de pago en el mercado y, de esta forma, la "economía moderna", que "se configura como una economía orientada monetariamente" García Cavero, Derecho Penal Económico, cit. (n. 40), p. 52. Incluye dentro de los delitos económicos la falsificación de datos de pertinencia o relevancia probatoria del $\$ 269$ del Código Penal alemán Tiedemann, Wirtschaftsstrafrecht, cit. (n. 37), números marginales $521 \mathrm{~s}$.

${ }^{76}$ Véase: Correia, Eduardo, Introdução ao Direito penal económico, en Direito pe- 
patrimoniales individuales del acreedor o de los acreedores del fallido ${ }^{77}$, pero que igualmente podrían ser entendidos como tipos penales lesivos, secundariamente, de una dimensión del orden (público) económico, a saber, el correcto funcionamiento del sistema crediticio ${ }^{78}$.

\section{La estafa como delito económico desde un punto de vista teleológico-} normativo.

Según las normas penales chilenas, para que el delito de estafa se configure no es necesario que se afecte el orden (público) económico: indispensable es que exista una lesión de los intereses patrimoniales de la víctima, que obedezca a una disposición patrimonial perjudicial determinada por error y que sea imputable al engaño típico del agente. De la misma forma, para que estemos ante una falsificación de instrumentos mercantiles o de un delito concursal, no se requiere una afectación de la economía, sino que de la funcionalidad del documento, tratándose de la primera, o bien, de los intereses patrimoniales del acreedor o de los acreedores del fallido, tratándose del segundo.

En el Código Penal chileno, la estafa en materia de crédito o de inversiones de capital carece de una tipificación autónoma. Ello no implica la impunidad de dichos comportamientos, sino que su sanción de acuerdo con las figuras comunes de estafa contempladas en dicho cuerpo normativo. Consiguientemente, tendrán que darse todos los requisitos típicos de la estafa común (engaño, error, disposición patrimonial, perjuicio patrimonial y relación de causalidad entre los aludidos elementos), a fin de castigar penalmente esos supuestos que, como sabemos, no exigen la afectación del orden (público) económico para su configuración.

De otro lado, el fraude de seguros, que ahora cuenta con una tipificación autónoma dentro de las normas del Código Penal ${ }^{9}$, no supone una afectación

nal económico e europeu: Textos doutrinários (Coimbra, Coimbra Editora, 1998), I, pp. 293 s., p. 296.

${ }^{77}$ Véase FeIjoo SÁnCHEZ, Bernardo, Cuestiones actuales de derecho penal económico (Montevideo - Buenos Aires, B de F, 2009), pp. 140 ss.; WiTTIG, Wirtschaftsstrafre$c h t$, cit. (n. 39), $\$ 23$, número marginal 6.

${ }^{78}$ Cfr. Отто, Grundkurs Strafrecht, cit. (n. 36), p. 328, número marginal 80; y Tiedemann, Wirtschaftsstrafrecht, cit. (n. 37), número marginal 413.

${ }^{79} \mathrm{La}$ Ley No 20.667, en su artículo 3, introduce un nuevo numeral 10 al artículo 470 del Código Penal chileno, que castiga con las penas del artículo 467: "10 A los que maliciosamente obtuvieren para si, o para un tercero, el pago total o parcialmente indebido de un seguro, sea simulando la existencia de un siniestro, provocándolo intencionalmente, presentándolo ante el asegurador como ocurrido por causas o en circunstancias distintas a las verdaderas, ocultando la cosa asegurada o aumentando fraudulentamente las pérdidas efectivamente sufridas". La norma además agrega, que "[s] i no se verifica el pago indebido por causas independientes de su voluntad, se aplicará el mínimo o, en su caso, el grado 
del orden (público) económico para que se entienda configurada la conducta delictiva. El fraude de subvenciones, en fin, antes de incidir negativamente en el orden (público) económico, lesiona el patrimonio estatal, distinguiéndose de la estafa tradicional fundamentalmente por el carácter público de su objeto jurídico. Así, mientras la estafa tutela el patrimonio privado ${ }^{80}$, que sirve ante todo a su propio titular, el fraude de subvenciones busca proteger el patrimonio público o fiscal, ${ }^{81}$ el cual existe, precisamente, para servir a la generalidad.

En todos los casos aludidos, que exista o pueda existir una afectación de la economía o del orden público económico, no resulta evidente. Sin perjuicio de las cifras involucradas, desde el punto de vista de los elementos del tipo penal de estafa no existe diferencia entre quien afirma (expresa o concluyentemente) una capacidad y voluntad de pago de un crédito, de una comida o de un servicio hotelero. Todos esos casos pueden ser sancionados de acuerdo con el artículo 468, si el agente usa nombre fingido; se atribuye poder, influencia o créditos supuestos; aparenta bienes, créditos, comisión, empresa o negociación imaginarios; o se vale de cualquier otro engaño semejante; o bien, de conformidad con el artículo 473 , si el sujeto activo ejecuta cualquier engaño que no se halle descrito en los anteriores artículos del Código Penal.

Que se engañe sobre el valor de una sociedad o sobre el valor de un bien cuyo precio se encuentra normativamente establecido, sólo se diferencia porque en el primer supuesto la víctima es un inversor y, en el segundo, un ciudadano cualquiera. Aquí también tendrá que aplicarse el artículo 468 o el artículo 473, según el objeto de referencia del engaño típico, y no en atención al sujeto concreto que resulte afectado con la defraudación.

En el fraude de seguros, su carácter de delito económico no resulta forzoso, tanto por el tamaño reducido del mercado asegurador chileno como porque los efectos perjudiciales de la conducta se limitan, en principio, únicamente

minimo de la pena", así como que "[l] a pena se determinará de acuerdo con el monto de lo indebidamente solicitado".

${ }^{80}$ Véase: Fischer, Thomas, Strafgesetzbuch und Nebengesetze (58 a edición, München, Beck, 2011), $\$ 263$, número marginal 3.

${ }^{81}$ Véase: Bajo, M - Bacigalupo, S. Derecho penal económico, cit. (n. 45), p. 289; Mayer Lux, Laura, Obtención fraudulenta de prestaciones estatales, en Revista de Derecho de la Pontificia Universidad Católica de Valparaiso, 32 ( $1^{\mathrm{er}}$ semestre de 2009), pp. 290 ss., con referencias ulteriores. Secundariamente se incluye como parte o aspecto de lo protegido en el fraude de subvenciones el "plan, proyecto o fin" para el cual se estableció la subvención [así Asúa BATARRITA, Adela, Estafa común y fraude de subvenciones: de la protección del patrimonio a la protección de la institución subvencional, en AA.VV, Hacia un Derecho penal económico europeo, Jornadas en honor del profesor Klaus Tiedemann (Madrid, Boletín Oficial del Estado, 1995), p. 147], fin que ha de desprenderse de la propia normativa que la creó. 
a la compañía aseguradora, extendiéndose sólo mediatamente a otros asegurados de la misma compañía. ${ }^{82} \mathrm{En}$ este caso, tendrá que aplicarse la nueva figura contemplada en el $\mathrm{N}^{\circ} 10$ del artículo 470 , atendida su especialidad en relación con los tipos de los artículos 468 y 473 CPen.

Que un delito sea económico no depende del sujeto que ejecute la conducta, del lugar donde se cometa o de la víctima concreta que resulte afectada con ella. Si fuera por eso, tendría que calificarse de delito económico el homicidio de un corredor de la bolsa o de un individuo cualquiera al interior de la bolsa, o bien, el hurto llevado a cabo por un asesor financiero. De otro lado, no porque el objeto jurídico de la estafa pueda tener un componente económico, además de jurídico -como postula la doctrina y jurisprudencia chilena mayoritarias al plantear un concepto mixto de patrimonio-, debe concluirse que la estafa es un delito económico. Si fuera por eso, hasta el delito de hurto tendría que ser considerado parte integrante de la criminalidad económica.

Para que la estafa pueda ser calificada como un delito económico debe afectarse el funcionamiento de la economía, producto de la incidencia de la conducta delictiva en los intereses patrimoniales de un gran número de personas concretas. La estafa como delito económico debe ser concebida como una figura de lesión del orden (público) económico ${ }^{83}$ y de los intereses patrimoniales de muchas personas determinadas o determinables. Lo que ella sanciona es un daño al correcto funcionamiento de la economía, que obedece a la afectación de los intereses patrimoniales de una cantidad importante de personas específicas, supuesto que la doctrina también denomina "estafas colectivas" $^{\prime \prime}$.

${ }^{82}$ Véase Piña Rochefort, Fraude de seguros, cit. (n. 73), p. 40, quien, en p. 41 de la obra indicada, sostiene que el fraude de seguros es "un delito contra el patrimonio de una especial trascendencia social" que se ubica "en la frontera de las estructuras clásicas que protegen el patrimonio y la delincuencia socioeconómica”.

${ }^{83}$ De otra forma Choclán Montalvo, El delito de estafa, cit. (n. 61), pp. 17 ss. Aquí, el término "lesión" está siendo empleado en el sentido de daño o de afectación del bien jurídico, no de destrucción o pérdida del mismo [similar Corcoy Bidasolo, Mirentxu, Delitos contra la salud de los consumidores, en Gimeno Jubero, Miguel Ángel (director), Derecho penal económico (Madrid, Consejo General del Poder Judicial, 2006), p. 220].

${ }^{84}$ Cfr. Fernández Albor, Estudios sobre criminalidad económica, cit. (n. 7), p. 48; Muñoz Conde, Francisco, Derecho penal. Parte especial (18 a edición, Valencia, Tirant lo Blanch, 2010), p. 439. 


\section{Consecuencias de Que la ESTAFA SEA CONSIDERADA COMO DELITO ECONÓMICO DE ACUERDO CON LAS NORMAS PENALES} CHILENAS

Las normas penales chilenas que consagran las diversas hipótesis de estafa no establecen diferencias desde el punto de vista de la sanción penal si, junto con afectar el bien jurídico individual subyacente a las mismas, se incide negativamente en el orden (público) económico. ${ }^{85} \mathrm{La}$ cuantía del perjuicio irrogado repercute en su consideración como simple delito o falta, así como en la sanción específica a aplicar. No se contempla, en cambio, una norma que imponga una pena mayor en atención al número de personas afectadas con la comisión del delito, como sí ocurre en el $\$ 263$ (3) $2^{86}$ del Código Penal alemán, o en los artículos $74.2^{87}$ y $250^{88} \mathrm{del}$ Código Penal español. En principio, y a falta de una disposición equivalente a las indicadas, la pena a aplicar en Chile en casos de estafas colectivas se determinará de acuerdo con las reglas generales. En esta materia son fundamentalmente cuatro las instituciones y reglas que resultan pertinentes: el concurso ideal de delitos, el delito continuado, el concurso material o real de delitos y la extensión del mal causado por el delito cometido.

${ }^{85}$ Es decir, no existe una figura básica, en que se afecta el patrimonio individual, y una figura agravada, en que además se lesiona el orden (público) económico.

${ }^{86}$ Dicha norma considera como supuesto "especialmente grave" de estafa, aquel que provoque un perjuicio patrimonial de grandes dimensiones o en que el agente haya actuado con la intención de causar un riesgo de perjuicio patrimonial a un gran número de personas, mediante una comisión reiterada de la conducta típica. Respecto de dicha hipótesis véase solamente FISCHER, Strafgesetzbuchund Nebengesetze, cit. (n. 80), § 263 , números marginales $215 \mathrm{~s}$.

${ }^{87}$ De acuerdo con el artículo 74.2 del Código Penal español, "[s] i se tratare de infracciones contra el patrimonio, se impondrá la pena teniendo en cuenta el perjuicio total causado. En estas infracciones el Juez o Tribunal impondrá, motivadamente, la pena superior en uno o dos grados, en la extensión que estime conveniente, si el hecho revistiere notoria gravedad y hubiere perjudicado a una generalidad de personas". En doctrina, el supuesto regulado por dicha norma es conocido como "delito masa". Para su aplicación respecto de la estafa véase: MuÑoz Conde, Derecho penal, cit. (n. 84), pp. 439 ss.

${ }^{88}$ Dicha norma establece supuestos agravados de estafa, siendo particularmente aplicable a las estafas colectivas el artículo 250.1., circunstancia 6a , del Código Penal español, según el cual, la pena del delito de estafa resultará agravada cuando la conducta "[r] evista especial gravedad, atendiendo al valor de la defraudación, a la entidad del perjuicio y a la situación económica en que deje a la víctima o a su familia”. Para la aplicación de dicha norma en relación con la aplicación del artículo 74.2., véase: CHOCLÁN MONtalvo, El delito de estafa, cit. (n. 61), pp. 221 s.; y Mestre, Esteban, Delitos contra el patrimonio y contra el orden socioeconómico, en LAMARCA, Carmen (coordinadora), Derecho penal. Parte especial (6a edición, Madrid, Colex, 2011), pp. 306 s. 
La regla del concurso ideal de delitos del artículo 75 tendrá que aplicarse en caso que se lesionen los intereses patrimoniales de las diversas víctimas de la estafa colectiva a través de un único engaño típico. Sin embargo, si la regla de la acumulación material de las penas prevista en el artículo 74 inciso $1^{089}$ importa una sanción inferior para el acusado, tendrá que aplicarse dicha regla con preferencia a la del artículo $75^{90}$, aun cuando se estime que el tenor de esta última sugiere otra cosa.En este punto seguimos la interpretación de Cury, según la cual, cuando la regla del concurso ideal sea más perjudicial que la de la acumulación, tendrá que aplicarse ésta, puesto que "si lo que se persigue por la norma del artículo 75 es conceder al autor un tratamiento más benévolo, resulta absurdo perseverar en darle aplicación aunque en la situación concreta lo perjudique" ${ }^{\prime 1}$.

Por su parte, si son varios los engaños cometidos en el contexto de una estafa colectiva, puede apreciarse un supuesto de delito continuado-que, como sabemos, no tiene un reconocimiento legal, pero sí doctrinal y jurisprudencial - y considerar la reiteración de engaños típicos constitutivos de estafa como un "único delito"92. Ello se ve favorecido por el carácter cuantificable del bien jurídico subyacente a dicho delito -los intereses patrimoniales de las víctimas-, lo cual permite "determinar la suma total a que el resultado asciende" 93 . Ahora bien, para que pueda apreciarse un delito continuado de estafa (colectiva) debe existir: $i$ ) unidad de sujeto activo; $i i$ ) pluralidad de acciones que, por sí mismas, satisfacen las exigencias típicas; iii) comisión en un contexto cronológico unitario o con una "cierta separación" "94; iv) comisión de delitos de la misma especie, esto es, que atenten contra un mismo bien

${ }^{89}$ De acuerdo con el inciso 1 del artículo 74 “[a]l culpable de dos o más delitos se le impondrán todas las penas correspondientes a las diversas infracciones”.

${ }^{90}$ En virtud del artículo 75 "[1] a disposición del artículo anterior no es aplicable en el caso de que un solo hecho constituya dos o más delitos, o cuando uno de ellos sea el medio necesario para cometer el otro.

En estos casos sólo se impondrá la pena mayor asignada al delito más grave”.

${ }^{91}$ Cury, Enrique, Derecho penal. Parte general ( 8 a edición, Santiago, Ediciones Universidad Católica de Chile, 2005), p. 662.

${ }^{92}$ Politoff, Sergio - Matus, Jean Pierre - Ramírez, María Cecilia, Lecciones de Derecho penal chileno, Parte general ( $2^{\text {a }}$ edición, Santiago, Editorial Jurídica de Chile, 2003), p. 453.

${ }^{93}$ Etcheberry, Alfredo, Derecho penal ( $3^{\text {a }}$ edición, Santiago, Editorial Jurídica de Chile, 1998), II, p. 114.

${ }^{94}$ Couso, Jaime, Art. 74, en Couso, Jaime - Hernández, Héctor (directores), Código Penal comentado. Parte general. Doctrina y jurisprudencia (Santiago, LegalPublishing, 2011), p. 639. 
jurídico; $\mathrm{y} v$ ) conexión entre las acciones en el sentido de que puedan ser entendidas como la vulneración fraccionada de una única norma ${ }^{95}$ prohibitiva.

No obstante, si la pena del delito continuado (de estafa) en el caso concreto importa una sanción mayor que la que correspondería de seguirse la regla del concurso material, tendrá que aplicarse esta última. Desde el punto de vista de la consideración de la estafa como delito económico, ello puede terminar acarreando penas más bien simbólicas, atendido el exiguo monto de lo defraudado respecto de cada víctima en particular. Así, de cometerse un sinnúmero de estafas-falta del artículo $494 \mathrm{~N}^{\circ} 19$, la acumulación aritmética a lo más supondrá una elevada multa, pero no puede transformar esas faltas, por numerosas que sean, en delito. No sólo porque no cabe aplicar una regla de reconocimiento doctrinal y jurisprudencial -comoel delito continuado-, descartando otra más benigna consagrada expresamente en la ley. También, en virtud de lo establecido en el artículo $451 \mathrm{CPen}$, según el cual: "En los casos de reiteración de hurtos, aunque se trate de faltas, a una misma persona, o a distintas personas en una misma casa, establecimiento de comercio, centro comercial, feria, recinto o lugar el tribunal calificará el ilícito y hará la regulación de la pena tomando por base el importe total de los objetos sustraídos, y la impondrá al delincuente en su grado superior".

Pues bien, y sin tomar en cuenta la desafortunada referencia al "delincuente", propia de un Derecho penal de autor, no puede extenderse analógicamente a la estafa-falta una regla contemplada sólo para el hurto(-falta). Ello, pone de relieve el sesgo clasista de la política criminal chilena, en la que dos comportamientos con idéntico marco penal ${ }^{96}$ y que pueden ser considerados como equivalentes, tanto desde el punto de vista del bien jurídico afectado como del comportamiento típico, terminan recibiendo un tratamiento penal completamente distinto: con penas injustas y desproporcionadas para el hurto, figura ligada con la "criminalidad callejera", y sorprendentemente benignas para la estafa, delito vinculado tradicionalmente con la "criminalidad de cuello blanco", de acuerdo con el concepto que de dicho término desarrolla Sutherland ${ }^{97}$.

En la etapa de determinación concreta de la cuantía de la pena el juez deberá, además, inclinarse por la sanción punitiva más alta dentro del marco penal aplicable, según el monto del perjuicio causado. Es decir, deberá tener en cuenta "la extensión del mal producido por el delito", de acuerdo con

${ }^{95}$ Así Cury, Derecho penal, cit. (n. 91), p. 656.

${ }^{96}$ Así se desprende de la comparación entre los artículos 446, relativo al hurto, y 467, que encabeza diversas hipótesis de estafa y hace aplicables sus penas a las conductas descritas en los artículos 468, 469 -en este caso, haciendo aplicable "el máximum" de dichas penas- y 470, todos del Código Penal chileno.

${ }^{97}$ Véase para ello el punto IV, 1. 
el artículo $69^{98}$ del Código Penal chileno, a fin de imponer un castigo que considere tanto el atentado individual -contra los intereses patrimoniales de las víctimas de la estafa colectiva-, como el supraindividual -respecto del orden (público) económico- que supuso la comisión de la conducta típica ${ }^{99}$. Todo ello, con las limitaciones indicadas para los supuestos en que cada defraudación sólo pueda ser considerada como una falta, no obstante nos encontremos ante un ataque cuantitativamente masivo de los intereses patrimoniales ajenos; y sin perjuicio de la regla especial para la aplicación de multas del artículo $70^{100}$ que, en casos de estafas colectivas, resultará más bien marginal, tanto por constituir una regla facultativa ${ }^{101}$ como, principalmente, por las características del hecho y las facultades (económicas) del hechor.

\section{BiBLIOGRAFÍA}

ACHENBACH, Hans, Wirtschaftskriminalität und Wirtschaftsstrafrecht. Gedanken zu einer terminologischen Bereinigung, en Feltes, Thomas - Pfeiffer, Christian - Steinhilper, Gernot (editores), Kriminalpolitik und ibre wissenschaftliche Grundlagen, Festschrift für Professor Dr. Hans-Dieter Schwind zum 70. Geburtstag (Heidelberg, C. F. Müller, 2006).

ADAM, Christopher, Internationalization and Integration of Financial and Capital Markets, en LeVy-Livermore, Amnon (editor), Handbookonthe Globalization of the World Economy (Cheltenham, Edward Elgar, 1998).

${ }^{98}$ De acuerdo con el artículo 69 "[d] entro de los límites de cada grado el tribunal determinará la cuantía de la pena en atención al número y entidad de las circunstancias atenuantes y agravantes y a la mayor o menor extensión del mal producido por el delito".

${ }^{99}$ En el mismo sentido: Martínez-Buján, Derecho penal económico y de la empresa. Parte general, cit. (n. 45), p. 163, con referencias ulteriores respecto del ordenamiento jurídico español.

${ }^{100}$ De acuerdo con el artículo 70 "[e]n la aplicación de las multas el tribunal podrá recorrer toda la extensión en que la ley le permite imponerlas, consultando para determinar en cada caso su cuantía, no sólo las circunstancias atenuantes y agravantes del hecho, sino principalmente el caudal o facultades del culpable. Asimismo, en casos calificados, de no concurrir agravantes y considerando las circunstancias anteriores, el juez podrá imponer una multa inferior al monto señalado en la ley, lo que deberá fundamentar en la sentencia./ Tanto en la sentencia como en su ejecución el Tribunal podrá, atendidas las circunstancias, autorizar al afectado para pagar las multas por parcialidades, dentro de un limite que no exceda del plazo de un año. El no pago de una sola de las parcialidades, hará exigible el total de la multa adeudada".

${ }^{101}$ Véase: Matus, Jean Pierre - van Weezel, Álex, 54 . De la aplicación de las penas, Artículos 50 a 73, en Politoff, Sergio - Ortiz, Luis (directores), Texto y comentario del Código Penal chileno. Libro Primero. Parte General (Santiago, Editorial Jurídica de Chile, 2002), I, p. 377. 
Aguirrezabal Grünstein, Maite, Algunas precisiones en torno a los intereses supraindividuales (colectivos y difusos), en Revista Chilena de Derecho, 33 (2006) 1.

Aller, Germán, Derecho penal económico y delitos del poder, en Anuario de Derecho Penal Económico y de la empresa, 2 (2012).

Alvarado Urízar, Agustina, Delitos de emprendimiento en el Código Tributario (Santiago, Librotecnia, 2011).

Asúa BATARrita, Adela, Estafa común y fraude de subvenciones: de la protección del patrimonio a la protección de la institución subvencional, en AA.VV, Hacia un Derecho penal económico europeo, Jornadas en honor del profesor Klaus Tiedemann (Madrid, Boletín Oficial del Estado, 1995).

Bajo, M. - Bacigalupo, S., Derecho Penal Económico (Madrid, Centro de Estudios Ramón Areces, 2001)

BARAtTA, Alessandro, Funciones instrumentales y simbólicas del derecho penal: una discusión en la perspectiva de la criminología crítica (1991), ahora, en El Mismo, Criminología y Sistema Penal (Montevideo - Buenos Aires, B de F, 2004).

Benavides Schiller, Andrés, Acerca de la corrupción pública y privada en España a la luz de los delitos contra la Administración Pública (Título XIX del Libro II CP Español), en Cuadernos de Politica Criminal, 108 (diciembre de 2012) 3.

Birnbaum, Johann Michael Franz, Sobre la necesidad de una lesión de derechos para el concepto de delito (traducción de José Luis Guzmán Dalbora, Montevideo - Buenos Aires, B de F, 2010).

BORINSKy, Mariano, Enfoque criminal y económico a propósito de prácticas anticompetitivas y vulneración de precios máximos, en Rubinska, Ramiro M. - SCHURJiN Almenar, Daniel (coordinadores), Derechopenaleconómico (Buenos Aires, Marcial Pons, 2010), I.

Bustos Ramírez, Juan, Obras Completas. Derecho penal. Parte general (2a edición, Santiago, Ediciones Jurídicas de Santiago, 2007), I.

Cervini, Raúl, Aproximación conceptual integrada al Derecho penal económico, en Rubinska, Ramiro M. - Schurjin Almenar, Daniel (coordinadores), Derecho penal económico (Buenos Aires, Marcial Pons, 2010), I.

Choclán Montalvo, José Antonio, El delito de estafa (Barcelona, Bosch, 2000).

Corcoy Bidasolo, Mirentxu, Delitos contra la salud de los consumidores, en Gimeno Jubero, Miguel Ángel (director), Derecho penal económico (Madrid, Consejo General del Poder Judicial, 2006).

Correia, Eduardo, Introdução ao Direito penal económico, en Direito penal económico e europeu: Textos doutrinários (Coimbra, Coimbra Editora, 1998), I.

Couso, Jaime, Art. 74, en Couso, Jaime - Hernández, Héctor (directores), Código Penal comentado. Parte general. Doctrina y jurisprudencia (Santiago, LegalPublishing, 2011).

Cury, Enrique, Derechopenal.Parte general ( 8 a edición, Santiago, Ediciones Universidad Católica de Chile, 2005).

Etcheberry, Alfredo, Derecho penal ( $3^{\text {a }}$ edición, Santiago, Editorial Jurídica de Chile, 1998), II.

FANELli, Andrea, La truffa (2a edición, Milano, Giuffrè, 2009).

Faria Costa, José de, Direito penal económico (Coimbra, Editorial Quarteto, 2004).

Faria Costa, José de, Noçôes fundamentais de Direito penal ( $3^{a}$ edición, Coimbra, Coimbra Editora, 2012).

Faria Costa, José de, O fenómeno da globalização e o Direito penal económico, en 
Almeida Costa, Mário Júlio - Ehrhardt Soares, Rogério - Castanheira Neves, António - Lopes Porto, Manuel Carlos - Faria Costa, José de (coordinadores), Estudos em Homenagem ao Prof. Doutor Rogério Soares (Coimbra, Coimbra Editora, 2001).

FeIjoo SÁnchez, Bernardo, Cuestiones actuales de derecho penal económico (Montevideo - Buenos Aires, B de F, 2009).

Fernandes Godinho, Inês - MAYER Lux, Laura, A burla como crime contra opatrimónio: superação de uma tautologia, en Revista Portuguesa de Ciência Criminal, 2 (2011).

Fernández Albor, Agustín, Estudios sobre criminalidad económica (Barcelona, Bosch, 1978).

Figueiredo Dias, Jorge de, Direito penal. Parte geral (2a edición, Coimbra, Coimbra Editora, 2007).

Fischer, Thomas, Strafgesetzbuch und Nebengesetze ( $58^{\text {a }}$ edición, München, Beck, 2011).

Foffani, Luigi, Criminalidad organizada y criminalidad económica, en Revista Penal, 7 (Universidad de Huelva, 2001).

Gaede, Karsten, IS 263-266b, en Leipold, Klaus - Tsambikakis, Michael - ZöLleR, Mark A. (editores), Anwaltkommentar StGB (Bonn, Deutscher Anwaltverlag, 2011).

García Cavero, Percy, Derecho penal económico. Parte general (2a edición, Lima, Grijley, 2007), I.

Greco, Luís, Gibt es Kriterien zur Postulierung eines kollektiven Rechtsguts? en HeinRich, Manfred - Jäger, Christian - AChenbaCh, Hans - Amelung, Knut Bottke, Wilfried - HAfFke, Bernhard - SchünemanN, Bernd - Wolter, Jürgen (editores), Strafrecht als Scientia Universalis, Festschrift für Claus Roxin zum 80. Geburtstag am 15. Mai 2011 (Berlin, De Gruyter, 2011), I.

Guzmán Dalbora, José Luis, "Estudio Preliminar" a Birnbaum, Johann Michael Franz, Sobre la necesidad de una lesión de derechos para el concepto de delito (Montevideo - Buenos Aires, B de F, 2010).

Guzmán Dalbora, José Luis, Contrabando y fraude aduanero (Valparaíso, Edeval, 1998).

Hefendehl, Roland, Kollektive Rechtsgüter im Strafrecht (Köln, Carl Heymanns Verlag, 2002).

Hernández Basualto, Héctor, La punibilidad de la colusión (secreta) de precios en el derecho chileno, en Politica Criminal, 7 (2012) 13.

Hormazábal Malarée, Hernán, Bien jurídico y estado socialy democrático de derecho ( $2^{a}$ edición, Santiago, LexisNexis, 2006).

Janssen, Gerhard, 5. Teil: Allgemeine Vermögensdelikte im Wirtschaftsstrafrecht, 1 . Kapitel: Betrug, en ACHenbaCH, Hans - Ransiek, Andreas (Editores), Handbuch Wirtschaftsstrafrecht (3a edición, München, C. F. Müller, 2012).

JimÉNEZ de Asúa, Luis, Crónica del crimen (7a edición, Buenos Aires, LexisNexis, 2005). KINDHÄUSER, Urs, Gefährdung als Straftat (Frankfurt am Main, Vittorio Klostermann, 1989).

KINDHÄUSER, Urs, Strafrecht Allgemeiner Teil ( 5 a edición, Baden-Baden, Nomos, 2011). KINDhäUser, Urs, Zur Legitimität der abstrakten Gefährdungsdelikte im Wirtschaftsstrafrecht, en SCHÜnemann, Bernd - SuÁREz GonzÁlez, Carlos (Editores), Bausteine des europäischen Wirtschaftsstrafrechts, Madrid-Symposium für Klaus Tiedemann (Köln, Carl Heymanns Verlag, 1995). 
Labatut Glena, Gustavo, Derecho penal (7 $7^{\mathrm{a}}$ edición actualizada por el profesor Julio Zenteno Vargas, Santiago, Editorial Jurídica de Chile, 2012), II.

Linares Estrella, Ángel, Un problema de la parte general del Derecho penal económico (Granada, Comares, 2002).

Lux, Laura, Obtención fraudulenta de prestaciones estatales, en Revista de Derecho de la Pontificia Universidad Católica de Valparaiso, 32 ( $1^{\mathrm{er}}$ semestre de 2009).

Martínez-Buján Pérez, Carlos, Derecho penal económico y de la empresa.Parte especial (4a edición, Valencia, Tirant lo Blanch, 2013).

Martínez-Buján Pérez, Carlos, Derecho penal económico y de la empresa. Parte general ( $2^{a}$ edición, Valencia, Tirant lo Blanch, 2007).

Marx, Michael, Zur Definition des Begriffs "Rechtsgut" (Köln, Carl Heymanns Verlag, 1972).

Matus, Jean Pierre - van Weezel, Álex, $\$ 4$. De la aplicación de las penas, Artículos 50 a 73, en Politoff, Sergio - Ortiz, Luis (directores), Texto y comentario del Código Penal chileno. Libro Primero. Parte General (Santiago, Editorial Jurídica de Chile, 2002), I.

Matus, Jean Pierre, Acerca de la actual falta de punibilidad en Chile de los acuerdos de precios, en Politica Criminal, 7 (2012) 14. [disponible en http://www.politicacriminal.cl/Vol_07/n_14/Vol7N14A3.pdf].

Merkel, Adolf, Die Lehre vom strafbaren Betruge, en El Mismo, Kriminalistische Abhandlungen (reimpresión de la edición de Leipzig de 1867, Glashütten im Taunus, Detlev Auverman, 1971), II.

Mestre, Esteban, Delitos contra el patrimonio y contra el orden socioeconómico, en LAMARCa, Carmen (coordinadora), Derecho penal. Parte especial (6a edición, Madrid, Colex, 2011).

Miranda, Rafael, Delitos contra el orden económico (Buenos Aires, Ediciones Pannedille, 1970).

Muñoz Conde, Francisco, Derechopenal. Parte especial (18 a edición, Valencia, Tirant lo Blanch, 2010).

Navarro Cardoso, Fernando, Algunas consideraciones sobre las estafas colectivas a los consumidores, en Revista del Poder Judicial, 50 (1998).

Ortiz Quiroga, Luis, Delincuencia económica, en AA.VV, Problemas Actuales de Derecho Penal (Temuco, Universidad Católica de Temuco, 2003).

Отто, Harro, Grundkurs Strafrecht, Die einzelnen Delikte ( $7^{\text {a }}$ edición, Berlin, De Gruyter, 2005).

Piña Rochefort, Juan Ignacio, Fraude de seguros. Cuestiones penales de técnica legislativa ( $2^{a}$ edición, Santiago, Editorial Jurídica de Chile, 2006).

Politoff, Sergio - Matus, Jean Pierre - Ramírez, María Cecilia, Lecciones de Derecho penal chileno. Parte especial ( $2^{a}$ edición, Santiago, Editorial Jurídica de Chile, 2005).

Politoff, Sergio - Matus, Jean Pierre - Ramírez, María Cecilia, Lecciones de Derecho penal chileno, Parte general (2a edición, Santiago, Editorial Jurídica de Chile, 2003).

RENGIER, Rudolf, Strafrecht Besonderer Teil, I: Vermögensdelikte (13 edición, München, Beck, 2011).

Righi, Esteban, Los delitos económicos (Buenos Aires, Ad Hoc, 2000).

Rivacoba, Manuel de, El delito de contrato simulado (Santiago, ConoSur, 1992).

Rodríguez Collao, Luis - Ossandón Widow, María Magdalena, Delitos aduaneros (Santiago, Editorial Jurídica de Chile, 2010). 
Rodríguez Collao, Luis - Ossandón Widow, María Magdalena, Delitos contra la función pública (2a edición, Santiago, Editorial Jurídica de Chile, 2008).

Rubio Lara, Pedro Ángel, Parte especial de Derecho penal económico español (una aproximación al estado de la cuestión en la doctrina y jurisprudencia españolas) (Madrid, Dykinson, 2006).

SснміDт, Eberhard, Das neuewestdeutsche Wirtschaftsstrafrecht (Tübingen, Mohr, 1950).

Schopenhauer, Arthur, Die Kunstsich Respektzuverschaffen (München, Beck, 2011).

Sternberg-Lieben, Detlev, Bien jurídico, proporcionalidad y libertad del legislador penal, en HeFendehl, Roland (editor), La teoría del bien jurídico ¿Fundamento de legitimación del Derecho penal o juego de abalorios dogmático? (Madrid, Marcial Pons, 2007).

Suárez González, Carlos, La función del Derecho penal y sus consecuencias para el genoma humano, en ZÚÑIGA RodRÍGUEZ, Laura - MÉNDEZ RodrígueZ, Cristina - Diego Díaz-Santos, María Rosario (coordinadoras), Derecho penal, sociedady nuevas tecnologías (Madrid, Colex, 2001).

Sutherland, Edwin - Cressey, Donald, Criminology (8a edición, Philadelphia, J. B. Lippincott, 1970).

Sutherland, Edwin, White Collar Crime, The Uncut Version (New Haven, Yale University Press, 1983).

Sutherland, Edwin, White Collar Criminality, en American Sociological Review, 5 (1940).

Tavares, Juárez, Bien jurídico y función en Derecho penal (traducción de Mónica Cuñarro, Buenos Aires, Hammurabi, 2004).

Tiedemann, Klaus, Tatbestandsfunktionen im Nebenstrafrecht, Untersuchungen $z u$ einem rechtsstaatlichen Tatbestandsbegriff, entwickelt am Problem des Wirtschaftsstrafrechts (Tübingen, Mohr, 1969).

Tiedemann, Klaus, WirtschaftsstrafrechtBesondererTeil ( $3^{a}$ edición, München, Vahlen, 2011).

TöввENs, Hans, Wirtschaftsstrafrecht (München, Vahlen, 2006).

Van Weezel, Alex, Delitos tributarios (Santiago, Editorial Jurídica de Chile, 2007).

Vidal Albarracín, Héctor Guillermo, Delitos aduaneros (2a edición, Corrientes, Mave, 2006).

WitTig, Petra, Wirtschaftsstrafrecht (2a edición, München, Beck, 2011). 